\title{
Cooling Roller Steady-state Heat Flux and Temperature Analysis in Amorphous Ribbon Preparing Process
}

\author{
Li Yongkang, Yang Yang, Song Yanming
}

Beihang University, Beijing 100191, China

\begin{abstract}
Temperature of cooling roller is a key issue affecting the quality of the amorphous ribbon. To this end, heat flux distribution acting on cooling roller outer wall was calculated by fluid dynamics software Fluent. Cooling roller steady temperature field was analyzed with a finite element method with heat flux boundary conditions. The cooling roller inner and outer wall temperature distribution was obtained and the temperature of cooling roller as a function of cooling roller thickness and water passage height was discussed. Results show that cooling roller outer wall temperature decreases with roller thickness and the cooling water passage height decrease; cooling roller inner wall temperature decreases with roller thickness increases and the cooling water passage height decreases. Meantime, the appropriate roller thickness and passage height were selected to keep both inner and outer wall temperature of cooling roller within the certain range. The study result provides theoretical support for cooling roller design and optimization.
\end{abstract}

Key words: amorphous ribbon; steady temperature field; heat flux; numerical simulation

Amorphous alloy has more excellent physical, chemical and mechanical properties than conventional crystalline alloy. Therefore, amorphous ribbon has very broad application prospects in electricity, aviation, aerospace and other fields. Planar flow casting (PFC) process is a major method for industrial preparation of amorphous ribbon owing to its capability of producing thin, wide and continuous amorphous ribbon ${ }^{[1]}$. Narasimhan ${ }^{[2]}$ invented PFC process to produce amorphous ribbon, which can produce continuous amorphous ribbon at $20 \sim 30 \mathrm{~m} / \mathrm{s}$, and adjust the ribbon width with demands, especially in a Fe based magnetic ribbon preparation process ${ }^{[3]}$.

In PFC process, a large amount of high temperature melt conduct heat transfer to the cooling roller resulting in cooling roller outer wall temperature rising sharply, which can affect roller cooling capacity and amorphous ribbon quality. Thus, in order to produce high quality amorphous materials, it is necessary to analyze influencing factors of cooling roller temperature and select the suitable parameter to keep cooling roller temperature within a specified range ${ }^{[4-8]}$. One of the key boundary conditions acting on cooling roller outer wall is heat flux. Pang ${ }^{[9]}$ proposed an equivalent average heat flux method to simulate cooling roller temperature field distribution and conducted experiments to verify its correctness. Guo ${ }^{[10]}$ simulated cooling roller steady-state temperature field in PFC process, got the cooling roller temperature field, and discussed the effect of roller diameter, thickness and speed on roller wall temperature. However, there is little information about the effect of heat flux distribution along cooling roller outer wall, cooling water passage height and roller thickness on cooling roller wall temperature.

The purpose of the present study is to discuss the heat flux distribution acting on cooling roller outer wall by a numerical simulation method. Steady thermal analysis was carried out to investigate the effect of parameter variables on cooling roller temperature distribution, and result will provide theoretical foundation for cooling roller design in PFC process.

\section{Numerical Simulation}

\subsection{Physical model}


Presently, the PFC process is a major method for industrial preparation of amorphous ribbon. Schematic illustration of PFC process is shown in Fig.1. Melt in crucible flowing through the nozzle slit was sprayed onto cooling roller by argon pressure and its own weight, and then cooled rapidly at $10^{6} \mathrm{~K} / \mathrm{s}$ to form amorphous ribbon. These processes released lots of heat in a very short time, and raised cooling roller inner and outer wall temperature by heat conduction; then amorphous ribbon was detached from the cooling roller by peeling equipment at $1 / 4$ circle of roller.

In the analysis above, there are two phases in amorphous preparation.

(1) From the position of melt injection to the position of ribbon detached from cooling roller (about 1/4 cir of roller), cooling roller outer wall mainly was subjected to heat flux from the melt and ribbon. So in this phase, cooling roller temperature analysis can use the equivalent heat flux $q$;

(2) From the position of the ribbon detached from cooling roller to next melt inject position (remaining 3/4 cir of roller), cooling roller was mainly subjected to heat exchange with ambient air. Air heat transfer coefficient is much smaller than that of the cooling water, so in this study, cooling roller heat transfer with ambient air can be ignored.

\subsection{Basic assumptions}

So as to facilitate and simplify the analysis process, the following assumptions are proposed:

(1) Ignoring the flow disturbance, the melt flow is laminar.

(2) Amorphous ribbon contacts well with cooling roller, no slip occurs between cooling roller, melt and nozzle wall.

(3) Because the air heat transfer coefficient is much smaller than that of cooling water, we do not consider heat convection with ambient air ${ }^{[11]}$.

\subsection{Mathematic model}

The mathematic model of ribbon formation established according to corresponding physical model of PFC process and relevant calculation parameters are shown in Table $1^{[12]}$. In order to improve the accuracy and computational efficiency, local mesh refinement meshing was set in contact area between puddle and cooling roller outer wall as shown in Fig.2a.

Calculation accuracy is affected by model grid size. This study takes contact temperature between cooling roller outer wall and puddle as target verified grid independence by puddle grid size $s=0.2,0.1,0.05,0.02,0.01 \mathrm{~mm}$, as shown in Fig.3. The contact temperature variation decreases with mesh size decreasing, When $s=0.02 \mathrm{~mm}$, the curve has become approximately horizontal. Considering computational efficiency, $s=0.02 \mathrm{~mm}$ was chosen as a puddle model meshing standard.

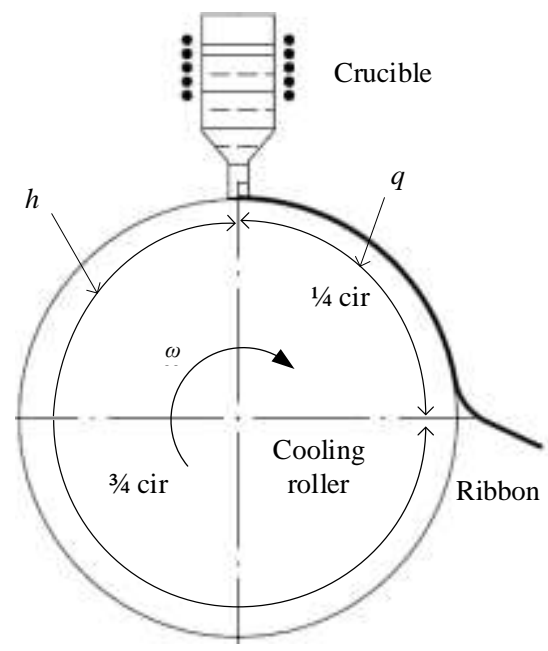

Fig.1 Schematic illustration of PFC

\subsection{Boundary conditions}

Boundary conditions are defined as shown in Fig.2b.

(1) Melt inlet: using pressure inlet boundary conditions, inlet temperature, $T_{\text {in }}=1533 \mathrm{~K}$; initial inlet pressure $P_{\text {in }}=20$ $\mathrm{kPa}$.

(2) Crucible wall: here the heat exchange does not occur, and the adiabatic boundary conditions are set.

(3) Cooling roller inner wall: heat convection between cooling roller and cooling water, heat transfer coefficient is $h$, which changes with the cooling water passage height.

(4) Air inlet and outlet: pressure inlet boundary, relative pressure is 0 .

(5) Cooling roller speed: $v=30 \mathrm{~m} / \mathrm{s}$.

\subsection{Solution method}

Discrete control equations are solved by the finite volume method. The SIMPLE algorithm are employed by solving Navier stoke equation to obtain the velocity and pressure distribution. An explicit time marching scheme is used to solve the VOF equation ${ }^{[11]}$.

\subsection{Heat flux distribution}

After simulation reached to steady state, cooling roller temperature and heat flux no longer changed as time. Steady state heat flux distribution, acting on the outer wall of the cooling roller, was extracted by the software Fluent, and post-processing module is shown in Fig.4.

It can be seen from the analysis result that cooling roller outer wall subjected to boundary condition can be divided into the following phases: $L 1-L 5$.

(1) Heat flux acting on cooling roller outer wall increased to maximum sharply at the front of alloy inlet position, where alloy has not been solidified, and cooling roller outer wall was subjected to the highest heat flux $q_{1}=4 \times 10^{8} \mathrm{~W} / \mathrm{m}^{2}$. 
Table 1 Calculation parameter

\begin{tabular}{cc}
\hline Item & Value \\
\hline Diameter of cooling roller, $D / \mathrm{mm}$ & 1600 \\
Rotation speed, $\mathrm{v} / \mathrm{m} \cdot \mathrm{s}^{-1}$ & 30 \\
Slit width of nozzle, $W / \mathrm{mm}$ & 0.6 \\
Nozzle-wheel gap distance, $G / \mathrm{mm}$ & 0.3 \\
Ejection pressure, $P_{\text {in }} / \mathrm{kPa}$ & 20 \\
Ejection temperature, $T_{\text {in }} / \mathrm{K}$ & 1533 \\
\hline
\end{tabular}
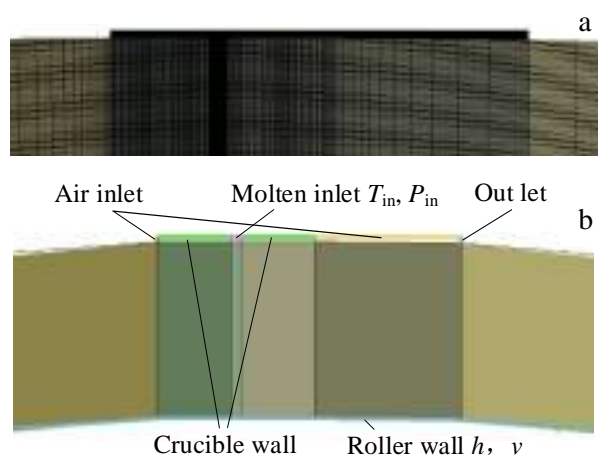

Fig.2 Mathematic model mesh system (a) and boundary conditions (b)

(2) The temperature of liquid alloy decreased rapidly by heat conduction due to contact with cooling roller, so heat flux acting on roller $L 2$ is much smaller than $L 1$, $q_{2}=2.5 \times 10^{8} \mathrm{~W} / \mathrm{m}^{2}$.

(3) Liquid alloy began to solidify when its temperature reached to solid-liquid boundary; meanwhile the heat flux decreased slowly with further decline of ribbon temperature, heat flux $q_{3}=2 \times 10^{8} \mathrm{~W} / \mathrm{m}^{2}$ when the temperature reached to freezing point.

(4) From position of forming ribbon to that of ribbon detached from the cooling roller, heat flux decreased with amorphous ribbon temperature decreasing owing to heat conduction and convection effect, heat flux of the position where amorphous ribbon was detached from the cooling roller $q_{4}=4.5 \times 10^{6} \mathrm{~W} / \mathrm{m}^{2}$.

(5) From the position of amorphous ribbon detached from the cooling roller to the alloy inlet position (remained $3 / 4$ roller cir), heat flux $q_{5}=0 \mathrm{~W} / \mathrm{m}^{2}$, since the amorphous ribbon is detached from the cooling roller, cooling roller outer wall is no longer affected by heat flux from ribbon.

Cooling roller heat flux have the maximum value in $L 2$, L3 phase, but the contact time is very short in these phases. Heat flux is 0 in $L 5$ phase, but contact time is very long, so heat flux mainly concentrate in $L 4$ phase, and heat flux distribution in a cycle is shown in Fig.5. Two cycles of the heat flux acting on cooling roller distribution were analyzed as shown in Fig.6. Cooling roller outer wall subjected to average heat flux $q_{\mathrm{a}}=2.05 \times 10^{6} \mathrm{~W} / \mathrm{m}^{2}$, which is consistent well with the literature result ${ }^{[12]}$.

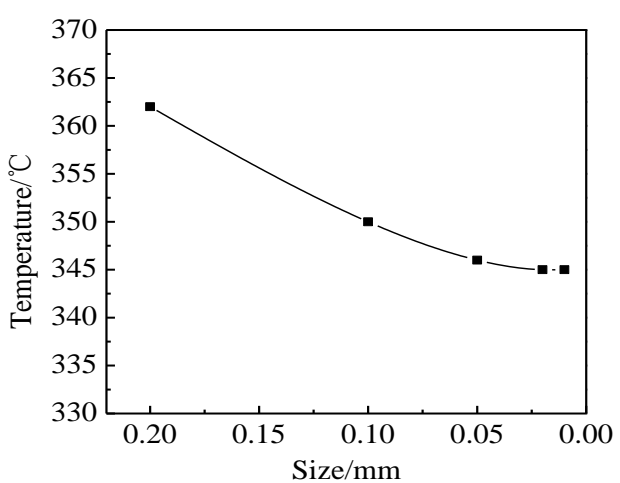

Fig.3 Verification of independence of grids in computation model

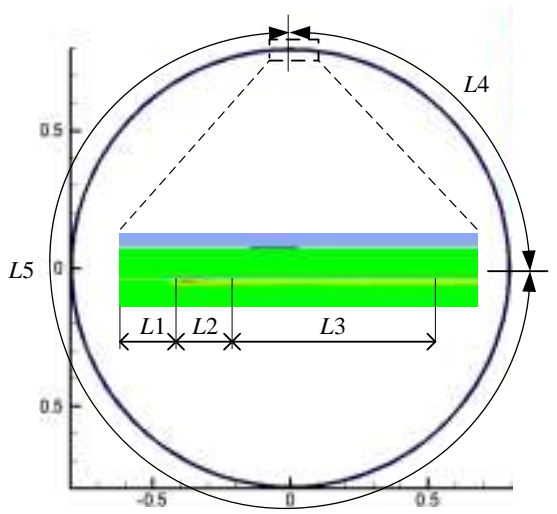

Fig.4 Heat flux distribution of roller outer wall

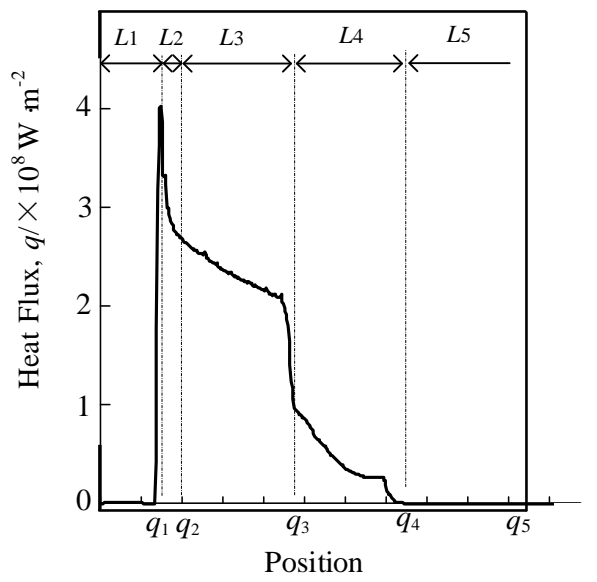

Fig.5 Heat flux distribution on roller out wall

\section{Steady Thermal Analysis}

\subsection{Parameter calculation}

Cooling roller water channel is the annular structure, and the section of the annular cooling channel is selected as shown in Fig.7. In the figure $t$ is the thickness of cooling roller, and $k$ is 


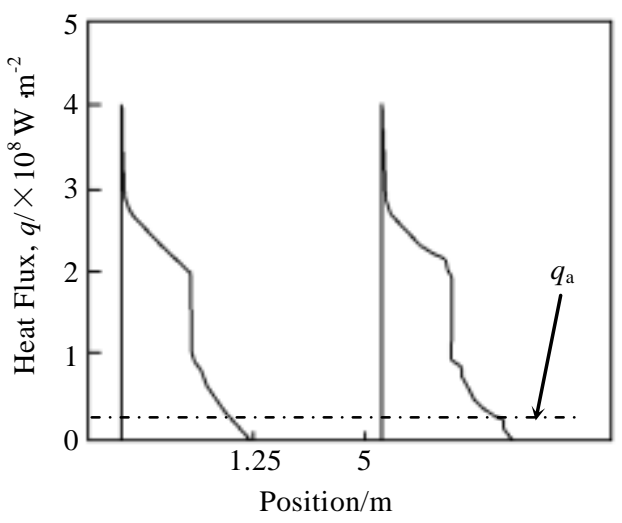

Fig.6 Heat flux distribution in two rotating cycles

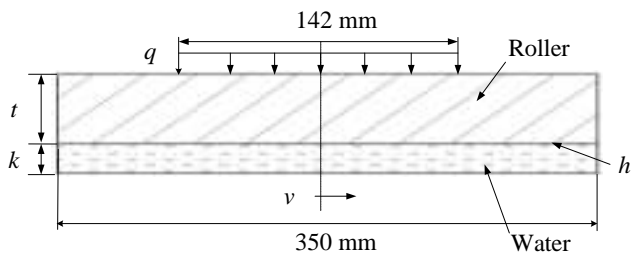

Fig.7 Cooling roller heat transfer model

the height of passage. Cooling roller suffers a periodic heat flux with roller rotation, equivalent heat flux $q_{\mathrm{a}}$ acting on contact area between ribbon and cooling roller. The heat transfer coefficient $h$ is imposed on surface between cooling water and roller inner wall.

(1) Equivalent diameter $d$

The cooling water passage is annular duct, and equivalent diameter $d$ is calculated as the following equation:

$$
\left.d=\left[D^{2}-(D-2 k)^{2}\right]\right) / D
$$

where $D$ is the outer diameter of the cooling channel, and $k$ is channel height.

(2) Convection heat transfer coefficient $h$

The inner wall of the cooling roller is cooled by cooling water convection. Heat transfer coefficient between the roller and cooling water is $h$, which can be calculated by Dittus-Boelter equation $(2)^{[12,13]}$ :

$$
\begin{aligned}
& h=0.023 \times \frac{\lambda}{d} \cdot\left(\frac{\rho u d}{\mu}\right)^{0.8} \cdot\left(\frac{C \mu}{\lambda}\right)^{0.8} \\
& R_{\mathrm{e}}=\frac{\rho u d}{\mu}
\end{aligned}
$$

where $\lambda, \rho, \mu, u$, and $C$ are the thermal conductivity, density, viscosity, velocity, and specific heat capacity of the cooling water, respectively.

Therefore, the relationship of heat transfer coefficient $h$ and the equivalent diameter $d$ is obtained according to Eqs.(2) and (3) as shown in Eq (4). The heat transfer coefficient $h$ acting on cooling roller inner wall changes with channel height $k$ when $R_{\mathrm{e}}=1.6 \times 10^{6}$, as shown in Fig. 8 .

$$
h=0.023 \times \frac{\lambda}{d} \cdot R_{\mathrm{e}}^{0.8} \cdot\left(\frac{C \mu}{\lambda}\right)^{0.8}
$$

It becomes obvious that the heat transfer coefficient $h$ decreases as channel height $k$ increases at constant Reynold's number.

\subsection{Temperature field distribution}

The steady temperature and heat flux distribution of cooling roller are obtained by a finite element method as shown in Fig.9. Point A, in the center position of cooling roller outside wall, has the highest temperature. The maximum temperature of the cooling roller inner wall at point $\mathrm{B}$. Points $\mathrm{C}$ and $\mathrm{D}$, the outer wall of the cooling roller have the maximum heat flux.

Heat flux acting on cooling roller is mainly along the vertical direction of the cooling roller at the centerline, but at contact boundary, heat flux is along the horizontal and vertical directions, as shown in Fig.9b.

It can be seen that the temperature of cooling roller outer wall increases significantly at contact area, but temperature of inner wall increases more gently. Both inside and outside roller wall have the highest temperature at the centerline, and temperature of cooling roller two ends is similar to surrounding air $28^{\circ} \mathrm{C}$.

In order to verify the accuracy of the numerical simulation, the outer wall temperature of cooling roller was measured at different positions by experiments, and the comparison results of experiments and simulation are shown in Fig.10. The simulation results are consistent well with the experiment, and the difference is less than $5 \%$. The simulation is larger than the experimental since the simulation does not consider the influence of ambient air flow heat transfer with roller. The comparing analysis indicates that the numerical simulation model and method with heat flux as boundary conditions is correct.

\subsection{Roller wall temperature}

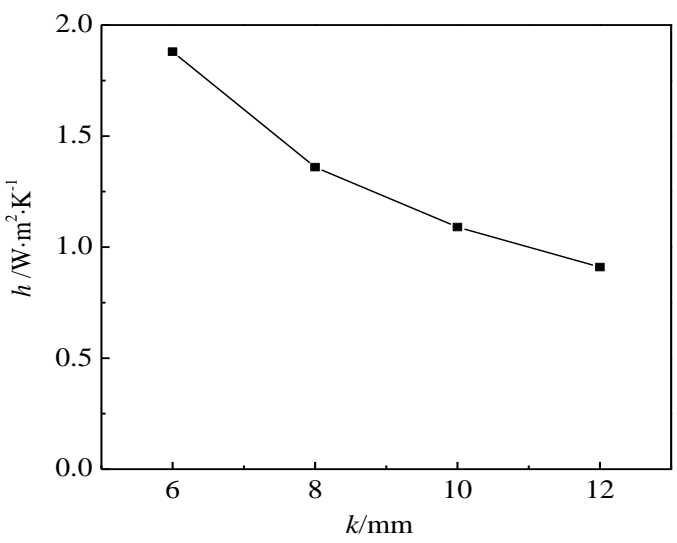

Fig.8 Heat transfer coefficient $h$ variations with channel height $k$ 


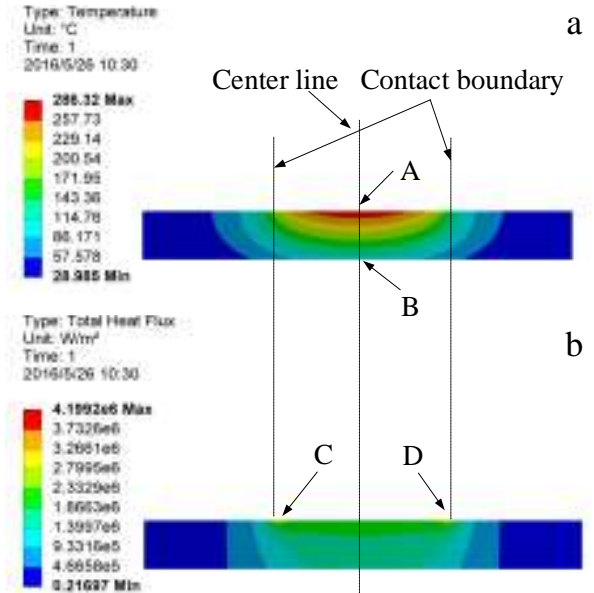

Fig.9 Cooling roller temperature (a) and heat flux (b) distribution in steady state

In order to analyze the effect of cooling roller water channel height $k$ and roller thickness $t$ on cooling roller wall temperature, we took cooling roller thickness $t=20,30,40$, $50 \mathrm{~mm}$ and channel height $k=5,6,8,12 \mathrm{~mm}$.

(1) Cooling roller outer wall temperature $T_{\mathrm{a}}$

The maximum temperature of the cooling roller outer wall $T_{\mathrm{a}}$ increases with channel height $k$ and roller thickness $t$ increasing, as shown in Fig.11. It is obvious that smaller cooling roller thickness and cooling water passage height can reduce the roller outer wall temperature when other parameters unchange.

(2) Cooling roller inner wall temperature $T_{\mathrm{b}}$

The maximum temperature of the cooling roller inner wall $T_{\mathrm{b}}$ increases with channel height $k$ increasing and roller thickness $t$ decreasing, as shown in Fig.12. In order to reduce the inner wall temperature of the cooling roller, we should increase roller thickness $t$ and decrease cooling water passage height $k$.

\subsection{Parameter optimization}

The quality of the amorphous ribbon is affected by cooling roller surface temperature, so it is necessary to maintain the average temperature of cooling roller outer wall below $200{ }^{\circ} \mathrm{C}$ and the average temperature of cooling roller inner wall below $100{ }^{\circ} \mathrm{C}^{[8]}$. Above all, the maximum temperature of the cooling roller outer wall should be lower than $300{ }^{\circ} \mathrm{C}$ and inner wall lower than $150{ }^{\circ} \mathrm{C}$. The plan meets the requirements obtained by multivariate analysis methods as shown in Table 2.

In amorphous ribbon preparing process, cooling roller outer wall formed pitting owing to eclipse injury from high temperatures alloy, which affects roller mechanical properties and quality of amorphous ribbon. Therefore, the roller requires grinding at constant time to keep the high

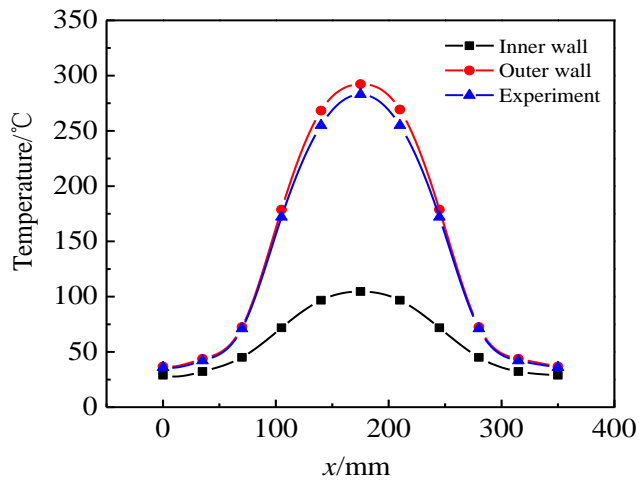

Fig.10 Temperature distribution of cooling roller wall

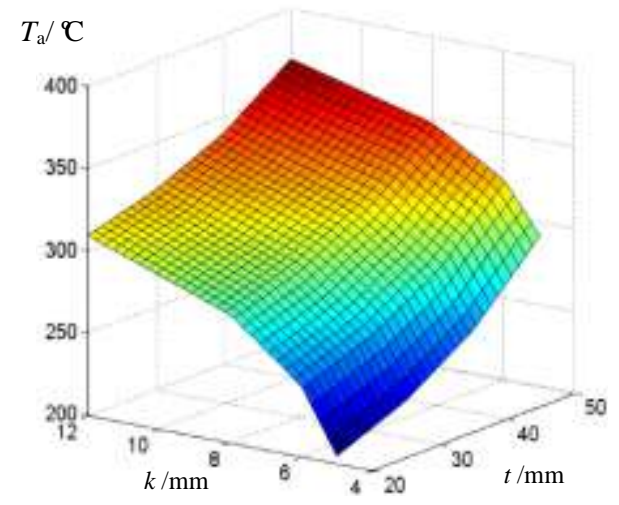

Fig.11 Roller outer wall maximum temperature varying with roller thickness $t$ and channel height $k$

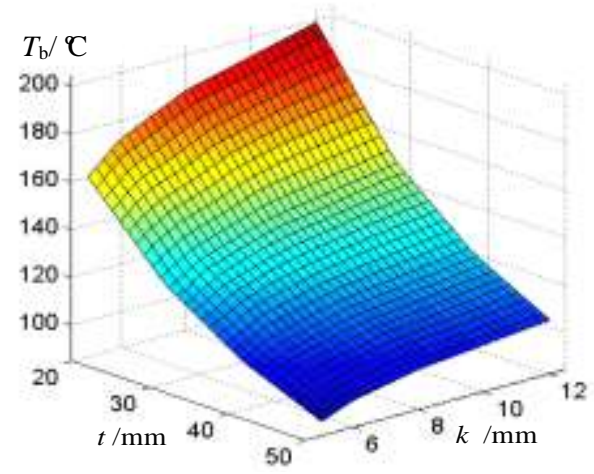

Fig.12 Roller inner wall maximum temperature varying with roller thickness $t$ and channel height $k$ 
Table 2 Program parameters

\begin{tabular}{ccccc}
\hline Plan & $k / \mathrm{mm}$ & $t / \mathrm{mm}$ & $T_{\mathrm{a}}$ & $T_{\mathrm{b}}$ \\
\hline 1 & 8 & 20 & 249 & 150 \\
2 & 6 & 20 & 222 & 123 \\
3 & 5 & 20 & 205 & 107 \\
4 & 8 & 30 & 283 & 143 \\
5 & 6 & 30 & 258 & 118 \\
6 & 5 & 30 & 243 & 102 \\
7 & 5 & 40 & 278 & 111 \\
\hline
\end{tabular}

quality of ribbon. Meanwhile, in order to strengthen the mechanical strength of the cooling roller, roller thickness $t$ should be larger within appropriate ranges. The channel height $k$ should be smaller within appropriate ranges owing to decrease of the total flow of cooling water. In summary, the plan 7 is reasonable according to the plans in Table 2, where channel height $k=5 \mathrm{~mm}$, the thickness of the cooling roller $t=40 \mathrm{~mm}$.

\section{Conclusions}

1) The temperature of cooling roller outer wall increases sharply where it contacts with the alloy, and then decreases quickly. The temperature of inner wall has the similar trends, but the temperature changes more gently. The temperature difference of cooling roller inner and outer wall is $8 \mathrm{~K}$ at two ends position, but difference reaches to $180 \mathrm{~K}$ at the center position.

2) Heat flux acting on cooling roller at central region can be approximated as one-dimensional heat conduction, and the thermal conduct direction from outside to inside, but the two-dimensional heat conduction at contact boundary is along the cooling roller axial and radial directions. Above all, when the width of amorphous ribbon is large, most of the heat transfers along the radial of the cooling roller, and heat conduction can be simplified using one-dimensional heat conduction.
3) The temperature of cooling roller outer wall decreases with the thickness of the roller and the cooling water passage height decreasing, while the inner wall temperature of roller decreases with the thickness of the roller increasing and the cooling water passage height decreasing. By comparison analysis, the appropriate roller thickness and passage height are selected to keep cooling roller both inner and outer wall temperatures within a certain range.

\section{References}

1 Song Y M, Yang Y. Journal of Beijing University of Aeronautics and Astronautics $[\mathrm{J}], 2015,41(3): 472$ (in Chinese)

2 Narasimhan M C. U S Patent, 4142571[P]. 1979

3 Willy H J, Zhao L Z, Wang G et al. Physics B: Condensed Matter[J], 2014, 437: 17

4 Srinivas M, Majumdar B, Phani K G et al. INTJ Metall Mater Trans $B[\mathrm{~J}], 2011,42(2): 370$

5 Sowjanya M, Reddy T K K. Journal of Materials Processing Technology[J], 2010, 214(9): 1861

6 Song Y M, Yang Y. Materials and Manufacturing Processes[J], 2015, 30(5): 631

7 Wang C B, Mitra A K. Journal of Heat Transfer[J], 2014, 136(7): 072101

8 Mehrabi K, Bruncko M, Mckay B J et al. Journal of Materials Engineering \& Performance[J], 2009, 18(5): 475

9 Pang Yunzhou, Shen Chuying, Pan Tingjian et al. Journal of Shanghai Iron and Steel Research[J], 1982, 3: 42 (in Chinese)

10 Guo Xi, Yan Mi. Rare Metal Materials and Engineering [J], 2015, 44(8): 2048 (in Chinese)

11 Liu H P, Chen W Z, Qiu S T et al. Metallurgical and Materials Transactions B[J], 2009, 40(3): 411

12 Zhang Jiongming, Zhang Li, Wang Xinhua et al. Acta Metallurgical Sinica[J], 2003, 39(12): 1285 (in Chinese)

13 Theisen E A, Davis M J, Weinstein S J et al. Chem Eng Sci[J], 2010, 65(10): 3249

\title{
非晶制带冷却辊热流与温度场数值模拟
}

\author{
李永康，杨 洋，宋言明 \\ (北京航空航天大学，北京 100191)
}

\begin{abstract}
摘 要: 冷却辊温度是影响非晶带材质量的关键因素, 为此应用流体动力学软件 FLUENT 模拟了冷却辊外壁面沿圆周方向的热流分布, 以此为边界条件, 采用有限元分析法对冷却辊进行了稳态温度场分析, 获得了冷却辊内外壁温度场分布, 讨论了冷却辊辊厚和冷却水 通道高度对冷却辊温度场的影响规律。结果表明: 减小冷却辊厚度可降低冷却辊外表面温度, 提高内表面温度; 减小冷却水通道高度 可以降低冷却辊内外表面温度。通过综合分析, 得到冷却辊内外表面温度在一定范围内的最优化设计方案, 为非晶带材冷却辊的设计 及优化提供理论支持。

关键词: 非晶带材; 稳态温度场; 热流; 数值模拟
\end{abstract}

作者简介: 李永康, 男, 1985 年生, 博士生, 北京航空航天大学机械工程与自动化学院, 北京 100191, 电话: 010-82339698, E-mail: buaalyk@qq.com 